\title{
Mutated SF3B1 is associated with transcript isoform changes of the genes UQCC and RPL31 both in CLLs and uveal melanomas
}

\author{
Alejandro Reyes ${ }^{1}$, Carolin Blume ${ }^{2}$, Vincent Pelechano ${ }^{1}$, Petra Jakob ${ }^{1}$, Lars M Steinmetz ${ }^{1,3}$, Thorsten
} Zenz ${ }^{2,4}$ and Wolfgang Huber ${ }^{*}$

\footnotetext{
${ }^{*}$ Correspondence: whuber@embl.de ${ }^{1}$ European Molecular Biology Laboratory, Genome Biology Unit, 69117, Heidelberg Germany Full list of author information is available at the end of the article
}

\begin{abstract}
Background: Genome sequencing studies of chronic lympoid leukemia (CLL) have provided a comprehensive overview of recurrent somatic mutations in coding genes. One of the most intriguing discoveries has been the prevalence of mutations in the HEAT-repeat domain of the splicing factor SF3B1. A frequently observed variant is predicted to cause the substitution of a lysine with a glutamic acid at position 700 of the protein (K700E). However, the molecular consequences of the mutations are largely unknown.

Results: To start exploring this question, we sequenced the transcriptomes of six samples: four samples of CLL tumour cells, of which two contained the K700E mutation in SF3B1, and CD19 positive cells from two healthy donors. We identified 41 genes that showed differential usage of exons statistically associated with the mutated status of SF3B1 (false discovery rate of $10 \%$ ). These genes were enriched in pathways related to interferon signaling and mRNA splicing. Among these genes, we found UQCC and RPL31; notably, a similar effect on these genes was described in a previously published study of uveal melanoma. In addition, while this manuscript was under revision, another study independently reported the common splicing signature of the gene UQCC in different tumour types with mutations in SF3B1.

Conclusions: Our results suggest common effects of isoform deregulation in the genes UQCC and RPL31 upon mutations in SF3B1. Additionally, our data provide a candidate list of potential isoform consequences of the SF3B1 (K700E) mutation in CLL, some of which might contribute to the tumourigenesis. Validation studies on larger cohorts and model systems are required to extend these findings.
\end{abstract}

Keywords: chronic lymphoid leukemia; SF3B1; differential exon usage

\section{Introduction}

Several DNA sequencing studies of chronic lymphocytic leukemia (CLL) revealed that the splicing factor SF3B1 accumulated somatic point mutations in about $10 \%$ of patients [1-3]. In most cases the mutations were located in the genomic regions coding for the C-terminal HEAT-repeat domain and in many cases, the mutations 
gave rise to specific amino acid substitutions. For instance, the substitution of a lysine to a glutamic acid at amino acid 700 of the protein (K700E) was prevalent in the tumour cells. In addition, the affected amino acids seemed to be clustered spatially in the 3D structure of the protein. These observations suggest that specific changes to the function of the protein could be one of the main drivers of tumour progression in CLL. Additionally, DNA sequencing studies have found recurrent mutations in SF3B1 in other malignancies, including myelodysplasia (with high incidence in a particular subgroup, RARS) $[4,5]$ and uveal melanomas $[6,7]$.

mRNA splicing is the process by which introns are removed from pre-mRNA molecules in order to produce fully mature transcripts. A crucial step of the splicing process is the recruitment of the U2 small nucleolar ribonucleic particle (U2 snRNP) to the branch point sequence: this results in base pairing between U2 snRNP and the pre-mRNA that allows the first chemical reaction of splicing to occur [8]. This recruitment is preceded by the binding of the protein A2AF to the pyrimidine tract and subsequent recruitment of SF3b 155 (the protein encoded by SF3B1) [9, 10]. In fact, either blocking the interaction of SF3b 155 to the pre-mRNA sequences using the anti-tumour drug spliceostatin A (SSA) or the knockdown of SF3B1 results in unstable recruitment of U2 snRNP, which leads to changes in splicing [11].

Additional studies have shown the relevance of SF3B1 in the regulation of splicing in different biological contexts. For instance, it has been shown that the interaction between SF3b 155 and the proteins Xfp144 and Rnf2 from the Polycomb group of genes is required for the repression of Hox genes during mouse development [12]. In a similar manner, it was shown that the loss of interaction between the proteins coded by the genes $P Q B P 1$ and $S F 3 B 1$ alters alternative splicing in mouse neurons and leads to neurite outgrowth defects [10]. These lines of evidence suggest that SF3B1 is necessary for the correct splicing of pre-mRNAs.

The presence of mutations in SF3B1 is correlated with adverse prognosis and shorter survival of CLL patients [13]. But despite their usefulness as clinical markers, the functional consequences of the mutations in SF3B1 are presently not well understood. It has been hypothesized that the mutations in the HEAT-repeat domain might affect the interaction of SF3b 155 with other co-factors and thus, splicing fidelity. Consistent with that hypothesis, it has been observed that mutations in SF3B1 are associated with the activation of abnormal 3' acceptor sites of specific genes in CLL tumour cells [1]. In a similar manner, transcriptome analyses of myelodysplastic syndromes and uveal melanomas have identified sets of genes with differential exon usage between tumours with mutations in SF3B1 and tumours with no mutations in this gene [7, 14].

Here, we aimed to start addressing the potential consequences on isoform regulation of the mutation predicted to cause the K700E substitution in the protein coded by $S F 3 B 1$ in CLL tumour cells. We generated transcriptome data from cells of two tumours with mutations in SF3B1, two tumours without mutations in SF3B1 and from cells from two healthy donors. We identified differences in isoform regulation 
that were associated with the SF3B1 mutation in 41 genes. We compare our results to previous studies of myelodysplastic syndromes and uveal melanomas with mutations in SF3B1.

\section{Results and Discussion}

Transcriptome-wide data reveal potential isoform regulation associated with mutations in SF3B1 in CLL tumour cells

We isolated RNA from B-CLL cells of four patients, of which two contained mutations in the SF3B1 gene (predicted to lead to the K700E substitution in the protein), and two had no mutation in SF3B1. Mutation status of each patient was determined by 454 pyrosequencing. We extracted RNA from CD19-purified cells isolated from the peripheral blood of two healthy donors and prepared cDNA libraries for sequencing (see Table $\mathrm{S} 1$ for detailed information regarding the samples). We used Illumina HiSeq 2000 to sequence 50 nt paired-end reads using a strand-specific protocol and obtained a total of $275,000,664$ sequenced fragments. We mapped the sequencing reads to the human reference genome (ENSEMBL release 68) using GSNAP (version 2013-05-09), allowing split alignments for exon-exon junctions [15]. We considered only uniquely mapping fragments for further analysis. To observe the expression of the SF3B1 alleles, we counted the number of mapped fragments in each sample supporting the evidence for the mutation. Based on this, we estimated that when the mutation was present, around half of the transcripts were transcribed from the variant allele (Figure 1). This estimate was consistent with the variant heterogeneity quantification of the tumours' DNA, as assessed by 454 genomic sequencing (also around 50\%, Table S1).

We asked, transcriptome-wide, whether specific differences in isoform regulation in the CLL tumour cells were associated with the presence of the SF3B1 K700E mutation. Therefore, we used DEXSeq to test for differences in exon usage (DEU) [16] between the tumour cells with the mutation K700E in SF3B1 compared to the tumour cells without the mutation and the healthy donors. Briefly, DEXSeq considered, for each exon, the ratio between the number of transcripts originating from the gene that contain the exon and the number of all transcripts originating from the gene. This allowed us to identify changes in relative exon usage independently from the fact that a gene could be differentially expressed. Using this approach, we identified a set of 50 exons in 41 genes with DEU at a false disovery rate (FDR) of $10 \%$. This represents an initial candidate list, and analysis of larger cohorts of patients is needed to confirm these associations.

To explore the functions of the genes whose isoform regulation was associated with the mutant SF3B1 samples, we mapped these genes to pathways annotated in REACTOME [17]. We found a statistically significant overrepresentation compared to a background set of genes that were also expressed in these cells, of pathways associated with mRNA splicing and translation at a false discovery rate of $10 \%$ (see Table S2). Interestingly, we also found a significant overrepresentation of the 
interferon signaling pathway, which is known to inhibit cell proliferation and whose aberrant regulation has been linked to aggressive cases of CLL [18]. These results are consistent with the notion that the SF3B1 K700E mutation could preferentially affect the isoform regulation of genes in particular biological pathways.

The SF3B1 mutation is associated with differential exon usage patterns seen both in uveal melanoma and CLL

Next we compared our results with those of two previously published transcriptomes. Notably, these studies used the same sequencing technology, had a similar study design (but in different malignancies) and also used the DEXSeq method to test for differences in exon usage.

Furney et al. [7] compared three SF3B1 mutant and nine SF3B1 wildtype uveal melanoma tumours and identified 34 exons differentially used in 21 genes $(10 \%$ FDR). Remarkably, we observed significant overlap between their list of differentially spliced genes and those identified in our study $\left(p=2 \cdot 10^{-3}\right.$, Fisher's exact test). Specifically, the genes $U Q C C$ and RPL31 overlapped with our hits. Furthermore, one out of the two 3' untranslated regions with DEU that Furney et al. reported for $R P L 31$, a gene coding for a ribosomal protein belonging to the $60 \mathrm{~S}$ ribosomal complex, was also seen as differentially used in our data (Figure 2). This, in principle, could have consequences for the localisation, stability or folding of the RNAs from this locus. Additionally, three out of the four exonic regions that we detected as significant for the chaperone $U Q C C$ were also detected to be differentially used in the uveal melanoma study. Its authors reported a decrease in the expression of the 3' end of this gene in uveal melanomas with mutated SF3B1, and we observed the same in the CLL tumour cells with mutated SF3B1 (Figure 3). Interestingly, this region partly codes for a chaperone domain that is conserved with yeast, where it appears to be required for the assembly of the protein ubiquinol-cytochrome $\mathrm{C}$ reductase [19]. In humans, genome-wide association studies have linked this gene to body growth [20].

Even though we are considering two rather different tumours, and the analyses were done in different laboratories, similar patterns of alternative isoform regulation of the UQCC and RPL31 genes were found to be associated with the mutated status of SF3B1 in both cases. We estimated that the probability of finding by chance that these same exon regions are differentially used was low $\left(p=1.4 \cdot 10^{-11}\right)$. Hence, our results suggest a link between the mutations in SF3B1 and the differential exon usage of these two genes that holds across tumour types. Additionally, while this manuscript was under revision, an independent publication validated (using RTqPCR) the common transcript isoform signature of $U Q C C$ upon SF3B1 mutations in both tumour types [21]

Visconte et al. reported 423 exons in 350 genes to be differentially used at an FDR of $5 \%$ between myelodysplasia patients with mutations in SF3B1 and one healthy donor [14]. However, the overlap of their list of genes with our list of genes was 
not larger than what would be expected by chance, and no common pattern was apparent.

\section{Conclusion}

As a data set relevant to the study of the effects on isoform regulation of the expression of mutant SF3B1 in CLL, we report transcriptome data from two CLL patients harboring the K700E mutation in SF3B1, two CLL patients without the mutation, as well as two healthy donor cells. Our results provide an initial list of DEU events that appear associated with the K700E mutation in SF3B1 in CLL (see Supporting Dataset S1). Our data rely on a very limited sample of tumours; substantially larger cohorts (e. g. tens or hundreds of tumours with and without the mutation) will be needed for a more reliable, more comprehensive list of events. A notable result of our analysis is the overlap of events seen here with those in a previous study of uveal melanomas [7], namely, differences in the usage of specific exonic regions of the genes $U Q C C$ and $R P L 31$. This effect was further confirmed for the gene $U Q C C$ by another independent study using RT-qPCR [21]. These effects could be a prevalent consequence of the mutations in the HEAT-repeat domain of SF3B1. The question of whether or not these effects play a causal role in tumorigenesis is not addressed by our analysis, but may merit further study.

\section{Methods}

\section{Ethics Statement}

Samples were acquired by informed written consent in accordance with the Declaration of Helsinki. Ethical and Institutional Board Review (IRB) approvals were obtained from the University Hospital of Heidelberg.

\section{Sample preparation}

Peripheral blood samples from four patients matching standard diagnostic criteria for CLL and featuring a high lymphocyte percentage (median: $98 \%$ ) were obtained from the University Hospital of Heidelberg. Mononuclear cells (MNCs) were isolated by centrifugation over Ficoll-Paque Premium (GE healthcare, Freiburg). MNCs from buffy coats of healthy donors obtained from the blood bank of the University Hospital of Heidelberg were further CD19-purified by magnetic activated cell sorting (MACS) according to the manufacturer's instructions (Miltenyi Biotech, Bergisch Gladbach) resulting in purities of $\geq 95 \%$ CD19+ cells. Clinical and laboratory data are summarized in Supporting Table S1. Exons of SF3B1, TP53, BRAF, MYD88 and NOTCH1 containing mutation hot spots were amplified and subjected to nextgeneration sequencing on the GS Junior 454 platform (Roche, Penzberg) as in [22]. In brief, genomic regions of interest were amplified from $30 \mathrm{ng}$ genomic DNA in two multiplex-PCRs with 11 primer pairs each. In the same reaction, linker tails were added for ligation of multiplex identifiers and 454-specific adaptors by a second PCR step on the combined pools. Primer sequences are available [22]. Bidirectional 
sequencing was performed using an emPCR Lib-A kit according to manufacturer's instructions with adaptations. Sequencing data were processed with GSRunProcessor (v.2.5/v.2.7), performing image and signal processing via the amplicon pipeline (Roche). Variants were identified with Amplicon Variant Analyzer (v.2.5/v.2.7) and annotated manually according to cDNA references from ENSEMBL Genome Browser. Mutations in SF3B1 were validated by conventional Sanger sequencing and were confirmed to be somatic mutations using whole exome sequencing.

\section{Strand-specific RNA-Seq library preparation}

Total RNA was isolated from $1 \cdot 10^{8}$ to $5 \cdot 10^{8}$ cells (depending on the sample) via standard trizol extraction. Strand specific RNA-Seq libraries were prepared as described in [23]. Briefly, polyadenylated RNA was isolated from $10 \mu \mathrm{g}$ of total RNA using Dynabeads Oligo (dT)25 (Invitrogen) according to the manufacturer's protocol. The poly(A) enriched RNA was fragmented by incubating the samples at $80^{\circ} \mathrm{C}$ for 4 minutes in the presence of RNA fragmentation buffer $(40 \mathrm{mM}$ Trisacetate, $\mathrm{pH}$ 8.1, $100 \mathrm{mM} \mathrm{KOAc}, 30 \mathrm{mM} \mathrm{MgOAc}$ ). The fragmented RNA was purified using 1.8X (v/v) Ampure XP Beads (Beckman Coulter Genomics) and eluted in $25 \mu \mathrm{l}$ Elution Buffer (EB) (10 mM Tris- $\mathrm{HCl}, \mathrm{pH} 8)$ according to manufacturer's protocol. $24 \mu \mathrm{l}$ of eluted RNA was reverse transcribed using $1 \mu \mathrm{l}$ of random hexamers (30 ng/ $/ \mathrm{l}$, Invitrogen). The samples were denatured at $70^{\circ} \mathrm{C}$ for 5 minutes and transferred to ice. Two $\mu \mathrm{l}$ dNTPs $(10 \mathrm{mM}), 8 \mu \mathrm{l} 5 \mathrm{X}$ first strand buffer (Invitrogen), $4 \mu \mathrm{l}$ DTT $(0.1 \mathrm{M}), 0.5 \mu \mathrm{l}$ actinomycin D $(1.25 \mathrm{mg} / \mu \mathrm{l})$ and $0.5 \mu \mathrm{l}$ RNaseOut (40 $\mathrm{U} / \mu \mathrm{l}$, Invitrogen) were added to each sample, and the samples were then incubated at $25^{\circ} \mathrm{C}$ for 2 minutes. Following this, $0.5 \mu$ l Superscript III reverse transcriptase (200 U/ $\mu \mathrm{l}$, Invitrogen) was added. The retrotranscription was carried out at $25^{\circ} \mathrm{C}$ for 10 minutes, at $55^{\circ} \mathrm{C}$ for 60 minutes, and inactivated at $75^{\circ} \mathrm{C}$ for 15 minutes. The samples were purified using 1.8X of Ampure XP beads and eluted in $20 \mu \mathrm{l} \mathrm{EB}$. For producing the second cDNA strand, $19 \mu \mathrm{l}$ of sample was mixed with $2.5 \mu \mathrm{l}$ of $10 \mathrm{x}$ NEBNext Second Strand Synthesis (dNTP-free) Reaction buffer (NEB), $1.5 \mu \mathrm{l}$ of dNTPs (containing dUTPs instead of dTTPs, $10 \mathrm{mM}), 0.5 \mu \mathrm{l}$ of RNaseH $(10,000$ $\mathrm{U} / \mathrm{ml}$ ) and $0.5 \mu \mathrm{l}$ of E.coli DNA polymerase I (10 U/ $\mu \mathrm{l}$, Fermentas). The samples were incubated at $16^{\circ} \mathrm{C}$ for 2.5 hours, $80^{\circ} \mathrm{C}$ for 20 minutes and purified with $1.8 \mathrm{X}$ Ampure XP beads, and eluted in $17 \mu \mathrm{l} \mathrm{EB}$. Two $\mu \mathrm{l}$ end repair buffer and $1 \mu \mathrm{l}$ end repair enzyme mix (NEBNext DNA Sample Prep Master Mix Set 1, NEB) were added, and the samples were incubated at $20^{\circ} \mathrm{C}$ for 30 minutes. The samples were purified using 1.8x Ampure XP and resuspended in $17 \mu \mathrm{l}$ EB. Two $\mu \mathrm{l} \mathrm{dA}$ tailing buffer (10X NEBuffer 2 from NEB and $0.2 \mathrm{mM}$ dATP) and $1 \mu \mathrm{l}$ Klenow Fragment 3' - 5' exonuclease $(5 \mathrm{U} / \mu \mathrm{l}, \mathrm{NEB})$ were added and the samples incubated at $37^{\circ} \mathrm{C}$ for 30 minutes. The samples were purified using 1.8x Ampure XP and resuspended in $20 \mu \mathrm{l}$ EB. $2.5 \mu \mathrm{l}$ 10X T4 DNA ligase buffer (NEB), $0.5 \mu \mathrm{l}$ multiplexed PE Illumina adaptors $(7 \mu \mathrm{M}$, Supporting Table S3) and $2 \mu \mathrm{l}$ T4 DNA ligase were added (2000 $\mathrm{U} / \mu \mathrm{l}, \mathrm{NEB})$ and incubated at $16^{\circ} \mathrm{C}$ for $1 \mathrm{~h}$. The dUTPs of the second strand were 
hydrolyzed by incubating the samples at $37^{\circ} \mathrm{C}$ for 15 min with $1 \mu \mathrm{l}$ USER enzyme (1 $\mathrm{U} / \mu \mathrm{l}, \mathrm{NEB})$ and 5 minutes at $95^{\circ} \mathrm{C}$. The samples were purified using $0.9 \mathrm{X}$ Ampure XP beads and eluted in $11 \mu \mathrm{l}$ EB. Enrichment PCR was performed using $5 \mu \mathrm{l}$ of sample, $25 \mu \mathrm{l}$ Phusion Master Mix 2x (NEB), $0.5 \mu \mathrm{l}$ each of oligos PE1.0 and PE2.0 (10 $\mu \mathrm{M}$, Illumina) and water up to $50 \mu \mathrm{l}$ final. The PCR program was 30 seconds at $98^{\circ} \mathrm{C}, 15$ cycles of $\left(10\right.$ seconds at $98^{\circ} \mathrm{C}, 30$ seconds at $65^{\circ} \mathrm{C}$ and 30 seconds at $72^{\circ} \mathrm{C}$ ) and 5 minutes at $72^{\circ} \mathrm{C}$. The PCR product was size-selected (average of $290 \mathrm{bp}$ ), and the libraries were submitted for Illumina sequencing.

\section{Bioinformatics}

We mapped the read fragments to the human reference genome from ENSEMBL (release 68) using GSNAP (version 2013-05-09) [15, 24]. For each sample, we tabulated the number of uniquely aligned fragments that overlapped with exon annotations from $E N S E M B L$ release 68 using scripts based on the python HTSeq library [25]. We used the generalized linear model framework implemented in DEXSeq version 1.9.1 to test for differences in exon usage between the samples containing the mutations in SF3B1 and the wild type allele samples [16].

To avoid biases associated with gene expression strength in further enrichment analysis, we generated a background set of genes that contained at least 600 sequenced fragment counts. We mapped the ENSEMBL gene identifiers to pathways annotated in REACTOME [17] and tested for overrepresentation of our hits compared to the background using Fisher's exact test. We corrected for multiple testing using the method of Benjamini and Hochberg [26]. We used the ENSEMBL Perl $A P I$ to convert protein domain coordinates annotated in PFAM to genomic coordinates [27]. Genomic ranges operations were performed using the Bioconductor package GenomicRanges [28], and visualizations of the genomic ranges were done using ggbio [29]. We visualized the coverage vectors and the expression of variants of SF3B1 using the Bioconductor package $h 5 v c$ [30]. We provide Supporting File S1 with a documented $R$ session with the code that was used to analyse the RNA-Seq data and to produce the figures.

\section{Availability of supporting data}

The RNA count data are available in the ArrayExpress database (www.ebi.ac.uk/ arrayexpress) under accession number E-MTAB-2025 and in the Bioconductor data package CLL.SF3B1.

List of abbreviations

DEU - differential exon usage; CLL - chronic lympoid leukemia; FDR - false disovery rate

Competing interests

The authors declare that they have no competing interests.

Author's contributions

WH, TZ and LMS designed the research. CB, VP, PJ and AR performed the research. TZ and CB selected the patients, isolated the biological samples and performed the mutational analysis. LMS, PJ and VP generated the RNA libraries for sequencing. AR and WH analysed the data and wrote the manuscript with input from all the authors. All authors read and approved the final manuscript. 
bioRxiv preprint doi: https://doi.org/10.1101/000992; this version posted July 13, 2014. The copyright holder for this preprint (which was not certified by peer review) is the author/funder, who has granted bioRxiv a license to display the preprint in perpetuity. It is made available under

\section{Acknowledgements}

We would like to thank EMBL's Genomics Core Facility for the RNA sequencing service and the Information Technology (IT) Core Facility for provision of computational infrastructure. WH and AR acknowledge funding from the European Commission through the Collaborative Research Project RADIANT.

\section{Author details}

${ }^{1}$ European Molecular Biology Laboratory, Genome Biology Unit, 69117, Heidelberg Germany. ${ }^{2}$ Department of Translational Oncology, National Centre for Tumour Diseases and German Cancer Research Centre, Heidelberg Germany. ${ }^{3}$ Stanford Genome Technology Center, Stanford University, Palo Alto, CA, USA. ${ }^{4}$ Department of Medicine V, University Hospital Heidelberg, Heidelberg Germany.

\section{References}

1. Quesada, V., Conde, L., Villamor, N., Ordonez, G.R., Jares, P., Bassaganyas, L., Ramsay, A.J., Bea, S., Pinyol, M., Martinez-Trillos, A., Lopez-Guerra, M., Colomer, D., Navarro, A., Baumann, T., Aymerich, M., Rozman, M., Delgado, J., Gine, E., Hernandez, J.M., Gonzalez-Diaz, M., Puente, D.A., Velasco, G., Freije, J.M., Tubio, J.M., Royo, R., Gelpi, J.L., Orozco, M., Pisano, D.G., Zamora, J., Vazquez, M., Valencia, A., Himmelbauer, H. Bayes, M., Heath, S., Gut, M., Gut, I., Estivill, X., Lopez-Guillermo, A., Puente, X.S., Campo, E., Lopez-Otin, C.: Exome sequencing identifies recurrent mutations of the splicing factor SF3B1 gene in chronic lymphocytic leukemia. Nat. Genet. 44(1), 47-52 (2012)

2. Wang, L., Lawrence, M.S., Wan, Y., Stojanov, P., Sougnez, C., Stevenson, K., Werner, L., Sivachenko, A., DeLuca, D.S., Zhang, L., Zhang, W., Vartanov, A.R., Fernandes, S.M., Goldstein, N.R., Folco, E.G., Cibulskis, K., Tesar, B., Sievers, Q.L., Shefler, E., Gabriel, S., Hacohen, N., Reed, R., Meyerson, M., Golub, T.R., Lander, E.S., Neuberg, D., Brown, J.R., Getz, G., Wu, C.J.: SF3B1 and other novel cancer genes in chronic lymphocytic leukemia. N. Engl. J. Med. 365(26), 2497-2506 (2011)

3. Quesada, V., Ramsay, A.J., Rodriguez, D., Puente, X.S., Campo, E., Lopez-Otin, C.: The genomic landscape of chronic lymphocytic leukemia: clinical implications. BMC Med 11, 124 (2013)

4. Yoshida, K., Sanada, M., Shiraishi, Y., Nowak, D., Nagata, Y., Yamamoto, R., Sato, Y., Sato-Otsubo, A., Kon, A., Nagasaki, M., Chalkidis, G., Suzuki, Y., Shiosaka, M., Kawahata, R., Yamaguchi, T., Otsu, M., Obara, N., Sakata-Yanagimoto, M., Ishiyama, K., Mori, H., Nolte, F., Hofmann, W.K., Miyawaki, S., Sugano, S., Haferlach, C., Koeffler, H.P., Shih, L.Y., Haferlach, T., Chiba, S., Nakauchi, H., Miyano, S., Ogawa, S.: Frequent pathway mutations of splicing machinery in myelodysplasia. Nature 478(7367), 64-69 (2011)

5. Papaemmanuil, E., Cazzola, M., Boultwood, J., Malcovati, L., Vyas, P., Bowen, D., Pellagatti, A., Wainscoat, J.S., Hellstrom-Lindberg, E., Gambacorti-Passerini, C., Godfrey, A.L., Rapado, I., Cvejic, A., Rance, R., McGee, C., Ellis, P., Mudie, L.J., Stephens, P.J., McLaren, S., Massie, C.E., Tarpey, P.S., Varela, I., Nik-Zainal, S., Davies, H.R., Shlien, A., Jones, D., Raine, K., Hinton, J., Butler, A.P., Teague, J.W., Baxter, E.J., Score, J., Galli, A., Della Porta, M.G., Travaglino, E., Groves, M., Tauro, S., Munshi, N.C., Anderson, K.C., El-Naggar, A., Fischer, A., Mustonen, V., Warren, A.J., Cross, N.C., Green, A.R., Futreal, P.A., Stratton, M.R., Campbell, P.J.: Somatic SF3B1 mutation in myelodysplasia with ring sideroblasts. N. Engl. J. Med. 365(15), 1384-1395 (2011)

6. Harbour, J.W., Roberson, E.D., Anbunathan, H., Onken, M.D., Worley, L.A., Bowcock, A.M.: Recurrent mutations at codon 625 of the splicing factor SF3B1 in uveal melanoma. Nat. Genet. 45(2), 133-135 (2013)

7. Furney, S.J., Pedersen, M., Gentien, D., Dumont, A.G., Rapinat, A., Desjardins, L., Turajlic, S., Piperno-Neumann, S., de la Grange, P., Roman-Roman, S., Stern, M.H., Marais, R.: SF3B1 mutations are associated with alternative splicing in uveal melanoma. Cancer Discov (2013)

8. Newby, M.I., Greenbaum, N.L.: A conserved pseudouridine modification in eukaryotic U2 snRNA induces a change in branch-site architecture. RNA 7(6), 833-845 (2001)

9. Gozani, O., Potashkin, J., Reed, R.: A potential role for U2AF-SAP 155 interactions in recruiting U2 snRNP to the branch site. Mol. Cell. Biol. 18(8), 4752-4760 (1998)

10. Wang, Q., Moore, M.J., Adelmant, G., Marto, J.A., Silver, P.A.: PQBP1, a factor linked to intellectual disability, affects alternative splicing associated with neurite outgrowth. Genes Dev. 27(6), 615-626 (2013)

11. Corrionero, A., Minana, B., Valcarcel, J.: Reduced fidelity of branch point recognition and alternative splicing induced by the anti-tumor drug spliceostatin A. Genes Dev. 25(5), 445-459 (2011)

12. Isono, K., Mizutani-Koseki, Y., Komori, T., Schmidt-Zachmann, M.S., Koseki, H.: Mammalian polycomb-mediated repression of Hox genes requires the essential spliceosomal protein Sf3b1. Genes Dev. 19(5), 536-541 (2005)

13. Oscier, D.G., Rose-Zerilli, M.J., Winkelmann, N., Gonzalez de Castro, D., Gomez, B., Forster, J., Parker, H., Parker, A., Gardiner, A., Collins, A., Else, M., Cross, N.C., Catovsky, D., Strefford, J.C.: The clinical significance of NOTCH1 and SF3B1 mutations in the UK LRF CLL4 trial. Blood 121(3), 468-475 (2013)

14. Visconte, V., Rogers, H.J., Singh, J., Barnard, J., Bupathi, M., Traina, F., McMahon, J., Makishima, H., Szpurka, H., Jankowska, A., Jerez, A., Sekeres, M.A., Saunthararajah, Y., Advani, A.S., Copelan, E., Koseki, H., Isono, K., Padgett, R.A., Osman, S., Koide, K., O'Keefe, C., Maciejewski, J.P., Tiu, R.V.: SF3B1 haploinsufficiency leads to formation of ring sideroblasts in myelodysplastic syndromes. Blood 120(16), 3173-3186 (2012)

15. Wu, T.D., Nacu, S.: Fast and SNP-tolerant detection of complex variants and splicing in short reads. Bioinformatics 26(7), 873-881 (2010) 
bioRxiv preprint doi: https://doi.org/10.1101/000992; this version posted July 13, 2014. The copyright holder for this preprint (which was not certified by peer review) is the author/funder, who has granted bioRxiv a license to display the preprint in perpetuity. It is made available under

16. Anders, S., Reyes, A., Huber, W.: Detecting differential usage of exons from RNA-seq data. Genome Res. 22(10), 2008-2017 (2012)

17. Croft, D., O'Kelly, G., Wu, G., Haw, R., Gillespie, M., Matthews, L., Caudy, M., Garapati, P., Gopinath, G., Jassal, B., Jupe, S., Kalatskaya, I., Mahajan, S., May, B., Ndegwa, N., Schmidt, E., Shamovsky, V., Yung, C., Birney, E., Hermjakob, H., D'Eustachio, P., Stein, L.: Reactome: a database of reactions, pathways and biological processes. Nucleic Acids Res. 39(Database issue), 691-697 (2011)

18. Tomic, J., Lichty, B., Spaner, D.E.: Aberrant interferon-signaling is associated with aggressive chronic lymphocytic leukemia. Blood 117(9), 2668-2680 (2011)

19. Shi, G., Crivellone, M.D., Edderkaoui, B.: Identification of functional regions of Cbp3p, an enzyme-specific chaperone required for the assembly of ubiquinol-cytochrome $\mathrm{c}$ reductase in yeast mitochondria. Biochim. Biophys. Acta 1506(2), 103-116 (2001)

20. Sanna, S., Jackson, A.U., Nagaraja, R., Willer, C.J., Chen, W.M., Bonnycastle, L.L., Shen, H., Timpson, N., Lettre, G., Usala, G., Chines, P.S., Stringham, H.M., Scott, L.J., Dei, M., Lai, S., Albai, G., Crisponi, L., Naitza, S., Doheny, K.F., Pugh, E.W., Ben-Shlomo, Y., Ebrahim, S., Lawlor, D.A., Bergman, R.N., Watanabe, R.M., Uda, M., Tuomilehto, J., Coresh, J., Hirschhorn, J.N., Shuldiner, A.R., Schlessinger, D., Collins, F.S., Davey Smith, G., Boerwinkle, E., Cao, A., Boehnke, M., Abecasis, G.R., Mohlke, K.L.: Common variants in the GDF5-UQCC region are associated with variation in human height. Nat. Genet. 40(2), 198-203 (2008)

21. Gentien, D., Kosmider, O., Nguyen-Khac, F., Albaud, B., Rapinat, A., Dumont, A.G., Damm, F., Popova, T., Marais, R., Fontenay, M., et al.: A common alternative splicing signature is associated with SF3B1 mutations in malignancies from different cell lineages. Leukemia, 1476-5551 (2014)

22. Hullein, J., Jethwa, A., Stolz, T., Blume, C., Sellner, L., Sill, M., Langer, C., Jauch, A., Paruzynski, A., von Kalle, C., Schmidt, M., Glimm, H., Zenz, T.: Next-generation sequencing of cancer consensus genes in lymphoma. Leuk. Lymphoma 54(8), 1831-1835 (2013)

23. Parkhomchuk, D., Borodina, T., Amstislavskiy, V., Banaru, M., Hallen, L., Krobitsch, S., Lehrach, H., Soldatov, A.: Transcriptome analysis by strand-specific sequencing of complementary DNA. Nucleic Acids Res. 37(18), 123 (2009)

24. Flicek, P., Ahmed, I., Amode, M.R., Barrell, D., Beal, K., Brent, S., Carvalho-Silva, D., Clapham, P., Coates, G., Fairley, S., Fitzgerald, S., Gil, L., Garcia-Giron, C., Gordon, L., Hourlier, T., Hunt, S., Juettemann, T., Kahari, A.K., Keenan, S., Komorowska, M., Kulesha, E., Longden, I., Maurel, T., McLaren, W.M., Muffato, M., Nag, R., Overduin, B., Pignatelli, M., Pritchard, B., Pritchard, E., Riat, H.S., Ritchie, G.R., Ruffier, M., Schuster, M., Sheppard, D., Sobral, D., Taylor, K., Thormann, A., Trevanion, S., White, S., Wilder, S.P., Aken, B.L., Birney, E., Cunningham, F., Dunham, I., Harrow, J., Herrero, J., Hubbard, T.J., Johnson, N., Kinsella, R., Parker, A., Spudich, G., Yates, A., Zadissa, A., Searle, S.M.: Ensembl 2013. Nucleic Acids Res. 41(Database issue), 48-55 (2013)

25. Anders, S., Pyl, P.T., Huber, W.: Htseq a python framework to work with high-throughput sequencing data (2014)

26. Benjamini, Y., Hochberg, Y.: Controlling the false discovery rate: a practical and powerful approach to multiple testing. Journal of the Royal Statistical Society. Series B (Methodological), 289-300 (1995)

27. Punta, M., Coggill, P.C., Eberhardt, R.Y., Mistry, J., Tate, J., Boursnell, C., Pang, N., Forslund, K., Ceric, G., Clements, J., Heger, A., Holm, L., Sonnhammer, E.L., Eddy, S.R., Bateman, A., Finn, R.D.: The Pfam protein families database. Nucleic Acids Res. 40(Database issue), 290-301 (2012)

28. Lawrence, M., Huber, W., Pages, H., Aboyoun, P., Carlson, M., Gentleman, R., Morgan, M.T., Carey, V.J.: Software for computing and annotating genomic ranges. PLoS Comput. Biol. 9(8), 1003118 (2013)

29. Yin, T., Cook, D., Lawrence, M.: ggbio: an R package for extending the grammar of graphics for genomic data. Genome Biology 13(8), 77 (2012)

30. Pyl, P.T., Gehring, J., Fischer, B., Huber, W.: h5vc: scalable nucleotide tallies with hdf5. Bioinformatics 30(10), 1464-1466 (2014)

Figures

Figure 1 SF3B1 variant expression. Each panel shows the data for one sample. The $y$-axis depicts the genomic coverage resulting from the alignment of the RNA-Seq fragments and the $x$-axis represents the genomic position relative to the position 198,266,834 of chromosome 2 (indicated by the vertical black lines), where the reference genome contains an adenine. The coverage consistent with the reference genome is coloured in gray. The first two samples express the variant that contains a guanine in around half of the transcripts (as indicated by the height of the red bar). This variant is predicted to cause the substitution K700E on the protein coded by SF3B1. 
bioRxiv preprint doi: https://doi.org/10.1101/000992; this version posted July 13,2014 . The copyright holder for this preprint (which was not certified by peer review) is the author/funder, who has granted bioRxiv a license to display the preprint in perpetuity. It is made available under aCC-BY 4.0 International license.

Figure 2 Differential exon usage of gene RPL31. The upper panel shows each exon region of the gene represented along the $x$-axis. The $y$-axis shows the counts for each sample normalised for sequencing depth. The lines from the samples with the mutation in SF3B1 are coloured in green, and the values from the wild-type samples are coloured in blue. The middle panel shows the flattened gene model (set of non-overlapping exon regions) along the genome ( $x$-axis). This flattened gene model was derived from the ENSEMBL annotated transcripts (lowest panel) as described in [16]. The exon detected to be significant for DEU in both our study (CLL) and in the uveal melanoma study [7] is coloured in magenta. The exon detected as significant only by the uveal melanoma study is coloured in orange. These exons correspond to 3' untranslated regions of transcripts (see lower panel).

Figure 3 Differential exon usage of gene UQCC. The upper panel shows each exon region of the gene represented along the $x$-axis. The $y$-axis shows the counts for each sample normalised for sequencing depth. The lines from the samples with the mutation in SF3B1 are coloured in green, and the values from the wild-type samples are coloured in blue. The middle panels depicts two copies of the flattened model, as defined in [16], derived from the transcripts annotated in ENSEMBL. In the upper flattened model, the exon regions detected to have significant DEU in our study are coloured in magenta. In the lower flattened model, the significant exon regions from the uveal melanoma study are coloured in magenta. The lowest panel presents the genomic regions coding for the protein domain PF03981 annotated in PFAM [27]. This domain is a highly conserved region of the protein Ubiquinol-cytochrome $C$ chaperone.

Additional Files

Table S1. Clinical and laboratory data of the CLL patients studied.

Table S2. Selected pathways enriched among genes with differential exon usage associated with the SF3B1 mutation (FDR 10\%).

Table S3. Oligonucleotide sequences used per sample.

Dataset S1. HTML report of the genes with DEU associated with the mutations in SF3B1

File S1. Documented R session with the program code needed to reproduce our analysis of the data and to generate the figures 

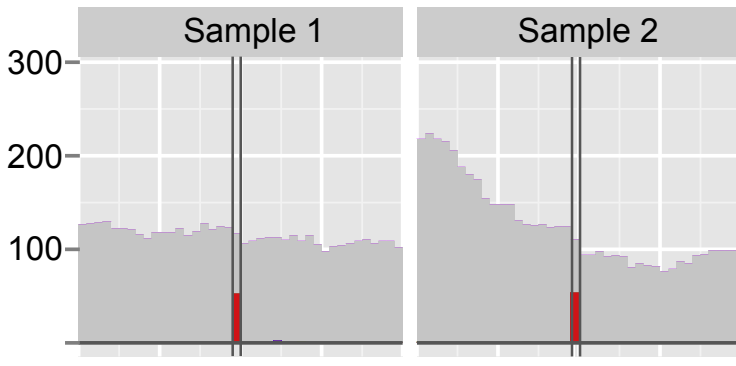

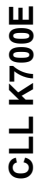
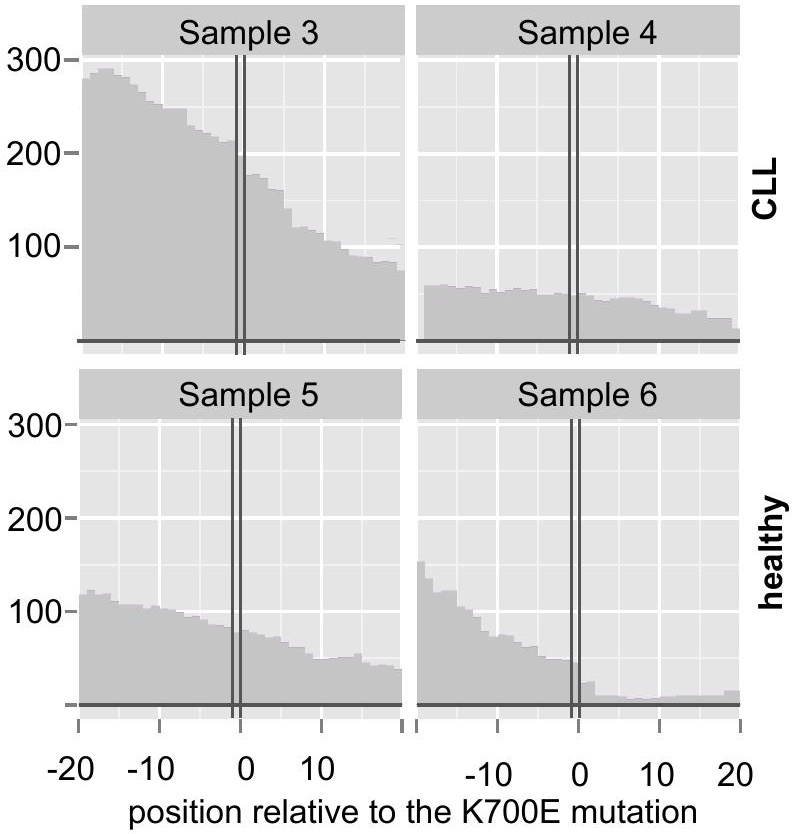
RPL31 +

mutated normal
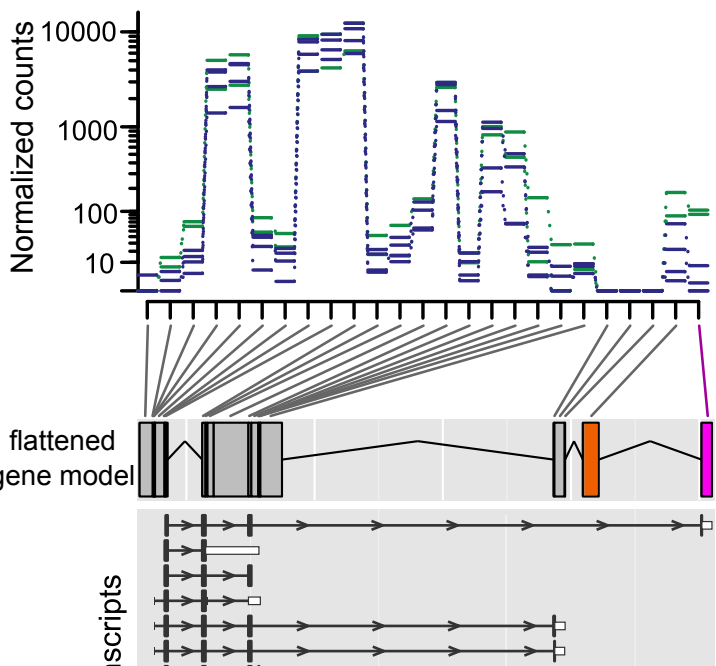

$\underset{\mathrm{\sigma}}{\mathrm{C}} \rightarrow \mathrm{H}$

$\stackrel{\text { t }}{t} \rightarrow$

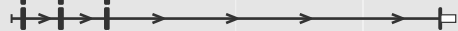

叶

$\square \rightarrow \longrightarrow \rightarrow H$

$\begin{array}{llll}101618177 & 101625616 & 101633055 & 101640494\end{array}$ 
